
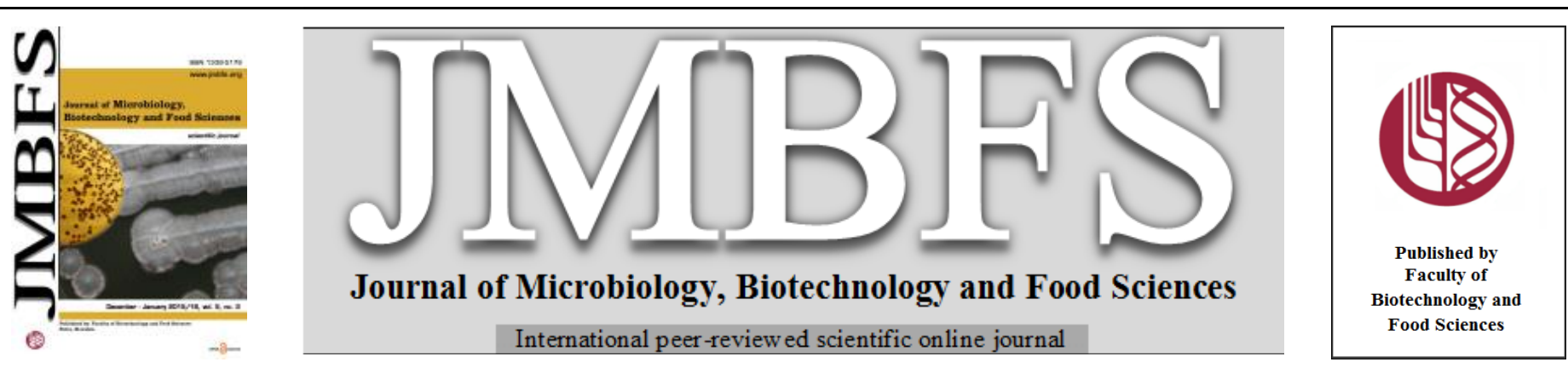

\title{
PREVENTIVE TREATMENT TO COMPLEMENT INFECTION CONTROL FOR CANDIDEMIA: IDENTIFICATION OF DIETARY SUPPLEMENTS THAT EFFECTIVELY INHIBIT THE GROWTH OF Saccharomyces AND B. megaterium WHILE PROLIFERATING E. coli
}

\author{
Durga Ganesh $*^{1}$ and Amanda Alonzo ${ }^{2}$ \\ Address(es): Ms. Durga Ganesh (Corresponding author) \\ ${ }^{1}$ Lynbrook High School, Student, 1280 Johnson Avenue, San Jose, California, United States of America, Phone: 408-366-7700. \\ ${ }^{2}$ Lynbrook High School, Science Teacher, 1280 Johnson Avenue, San Jose, California, United States of America.
}

*Corresponding author: thevoiceofstrings@gmail.com

doi: 10.15414/jmbfs.2015/16.5.3.254-258

ARTICLE INFO

Received 11.5. 2015

Revised 20. 9. 2015

Accepted 8. 10. 2015

Published 1. 12. 2015

Regular article

open $\mathcal{O}$ access

\begin{abstract}
Fungal infections have a crude mortality rate of $40 \%$ among immunocompromised patients, who are very susceptible due to drug resistant yeast strains and delayed diagnosis. In fact, in the United States alone, annual therapeutic treatments cost $\$ 2.8$ billion. This study aims to develop preventive treatments to complement established infection control for fungal infections. The hypothesis was that the combination of probiotics with cinnamon would be the most effective treatment. Various combinations and concentrations of overthe-counter supplements were evaluated in their ability to inhibit yeast and detrimental bacterial growth while proliferating beneficial bacteria. Saccharomyces, E. coli, and B. megaterium were grown in petri dishes to represent detrimental yeast, beneficial bacteria, and detrimental intestinal bacteria respectively. By measuring the zone of inhibition, this study shows that probiotics recreate an oxygenated, nonacidic, and beneficial bacterial habitat without interfering with the antifungal. The combination of oil of oregano (Origanum syriacum var. bevanii) with acidophilus was the most effective treatment, not supporting the hypothesis. Overall, taking oil of oregano and acidophilus with the antibiotic regimen may reduce the risk of developing fungal infections. Further research into understanding the underlying mechanism of these results and evaluating the clinical implications of this combination is recommended.
\end{abstract}

Keywords: Candidemia, antifungal, antibiotic regimen, oil of oregano, acidophilus

\section{INTRODUCTION}

Despite well-established therapeutic antifungal treatment classes such as polyenes, azoles, and echinocandins (Kauffman et al., 2014; Tani et al., 2012; Spampinato et al., 2013), the estimated annual cost to treat fungal infections in the United States is estimated at $\$ 2.8$ billion (Wilson et al., 2002; Fridkin 2005). About 300 in 1.5 million species of fungi are known to be dangerous to humans (Hawksworth, 2001). However, only a few classes of antifungal agents are currently available in oral and intravenous forms. Most deadly fungal infections either originate in a hospital setting (nosocomial) or target patients with weak immune systems (Zautis et al., 2005; Alangaden, 2011; Puzniak et al., 2004). The latter class includes premature babies, the elderly, patients with preexisting conditions such as the Human Immunodeficiency Virus (HIV), and patients taking immunosuppressive drugs for cancer treatment or organ/stem cell transplantation (Warnock, 2007; Mikulska et al., 2012; Bassetti et al., 2011; Horn et al., 2009).

An untreated or drug resistant yeast strain entering the blood stream can lead to Candidemia. The gastrointestinal tract is the predominant source of Candidemia (Nucci et al., 2001; Miranda et al., 2009). Intestinal yeast overgrowth is commonly induced through antibiotics or immunosuppressive usage, where beneficial bacteria are killed off, providing the ideal acidic environment for yeast to grow. The resulting inflammation and intestinal permeability leads to Candidemia (Kumar et al., 2013; Jensen et al., 2014). In critically ill patients, a corroboration has been established between high exposure to antibiotics and increased risk of invasive Candida infections (Mikulska et al., 2012). A significant percentage of Candidemia goes undetected in its early stages due to non-specific symptoms and a low diagnostic yield of traditional blood cultures (Zautis et al., 2005; Mikulska et al., 2012). Thus, there is a need for effective natural preventive treatments that can be adapted to peoples' diets without side effects. Potential side effects of therapeutic antifungal treatments range from abdominal pain, diarrhea, and indigestion to allergic reactions (NHS choices, 2015), but natural antifungals tend to have only minor, less fatal side effects. This study addresses preventive treatment to complement established infection control and preemptive treatment strategies for combatting yeast infections.
Different combinations and concentrations of over-the-counter supplements were evaluated to determine the treatment that would inhibit yeast and detrimental bacterial growth while aiding the proliferation of beneficial intestinal bacteria. Saccharomyces was used to represent fungi. B. megaterium, a common bacteria found in dirt, was chosen to represent detrimental bacteria. E. coli was utilized to represent beneficial intestinal bacteria.

We hypothesized that optimal results would be achieved when yeast and bacteria are treated with the combination of probiotics and cinnamon (Cinnamomum verum). Cinnamon and probiotics are widely advertised as over-the-counter dietary supplements that cure fungal and intestinal health ailments. However, researchers have documented mixed findings on the health benefits of both cinnamon (Wang et al., 2012; Wang et al., 2005; EBSCO Complementary and Alternative Medicine Review Board, 2014) and probiotics (Gorbach, 2006; Lucak, 2010; Rolf, 2000; Collado et al., 2009; Ballakrishnan et al., 2012). Garlic and oil of oregano have been reported to display antifungal properties (Bakker, 2012). Lactobacillus acidophilus (acidophilus) is an established probiotic (Bakker, 2012). This study aims to test the effectiveness of these substances as potential antifungals, as well as their efficacy in conjunction with probiotics.

\section{MATERIAL AND METHODS}

\section{Antifungal and Probiotic Supplements}

Garlic, cinnamon, caprylic acid, and oil of oregano were the four over-thecounter, antifungal supplements that were evaluated as treatments. Acidophilus was used as a representative probiotic supplement. Two concentrations (one and two tablets each) of these seven treatments were evaluated. In addition, two additional supplement combinations were created by compounding oil of oregano with caprylic acid and oil of oregano with acidophilus. Each of these combinations were tested with two different concentrations (Table 1). Treatment was not added to the negative control (Burton et al., 1997), and the positive control had tetracycline (antibiotic) (U.S. National Library of Medicine, 2010; Klajn, 1996) added to the bacterial plates. Thus, a total of 16 different treatments 
for bacterial plates and 15 different treatments for yeast plates were evaluated. The treatment concentrations for the supplements is listed in Table 1.

Table 1 Concentrations of the active ingredients of the treatments evaluated for this experiment along with the chemical formulas of the active ingredients are listed.

\begin{tabular}{|c|c|c|}
\hline Supplement & $\begin{array}{l}\text { Chemical } \\
\text { Formula }\end{array}$ & Treatment Concentration \\
\hline \multirow{2}{*}{ Garlic } & \multirow{2}{*}{$\mathrm{C}_{6} \mathrm{H}_{10} \mathrm{OS}_{2}$} & $500 \mathrm{mg}$ (1 tablet) \\
\hline & & $1000 \mathrm{mg}$ (2 tablets) \\
\hline \multirow{2}{*}{ Cinnamon } & \multirow{2}{*}{$\mathrm{C}_{11} \mathrm{H}_{13} \mathrm{NO}$} & $102.5 \mathrm{mg}$ (1 tablet) \\
\hline & & $205 \mathrm{mg}$ (2 tablets) \\
\hline \multirow{2}{*}{ Caprylic Acid } & \multirow{2}{*}{$\mathrm{C}_{8} \mathrm{H}_{16} \mathrm{O}_{2}$} & $541 \mathrm{mg}$ (1 tablet) \\
\hline & & $1082 \mathrm{mg}$ (2 tablets) \\
\hline \multirow{2}{*}{ Oil of Oregano } & \multirow{2}{*}{$\mathrm{C}_{10} \mathrm{H}_{14} \mathrm{O}$} & $500 \mathrm{mg}$ ( 1 tablet $)$ \\
\hline & & $1000 \mathrm{mg}$ (2 tablets) \\
\hline \multirow{2}{*}{ Acidophilus } & \multirow[b]{2}{*}{-} & 50 million ( 1 tablet $)$ \\
\hline & & 100 million (2 tablets) \\
\hline $\begin{array}{l}\text { Oil of Oregano with Caprylic } \\
\text { Acid } \\
\text { (One Tablet each) }\end{array}$ & \multirow{2}{*}{$\begin{array}{c}\mathrm{C}_{10} \mathrm{H}_{14} \mathrm{O}+ \\
\mathrm{C}_{8} \mathrm{H}_{16} \mathrm{O}_{2}\end{array}$} & $\begin{array}{l}500 \mathrm{mg} \text { ( } 1 \text { tablet }) \\
\& 541 \mathrm{mg} \text { (1 tablet })\end{array}$ \\
\hline $\begin{array}{l}\text { Oil of Oregano with Caprylic } \\
\text { Acid } \\
\text { (Two Tablets each) }\end{array}$ & & $\begin{array}{l}1000 \mathrm{mg} \text { (2 tablets) } \\
\& 1082 \mathrm{mg} \text { (2 tablets) }\end{array}$ \\
\hline $\begin{array}{l}\text { Oil of Oregano with } \\
\text { Acidophilus } \\
\text { (One Tablet each) }\end{array}$ & \multirow{2}{*}{$\mathrm{C}_{10} \mathrm{H}_{14} \mathrm{O}$} & $\begin{array}{c}500 \mathrm{mg} \text { ( } 1 \text { tablet }) \\
\& 50 \text { million ( } 1 \text { tablet })\end{array}$ \\
\hline $\begin{array}{l}\text { Oil of Oregano with } \\
\text { Acidophilus } \\
\text { (Two Tablets each) }\end{array}$ & & $\begin{array}{c}1000 \mathrm{mg} \text { ( } 2 \text { tablets }) \\
\& 100 \text { million ( } 2 \text { tablets })\end{array}$ \\
\hline None (Negative Control) & - & - \\
\hline $\begin{array}{l}\text { Tetracycline (Positive } \\
\text { Control) }\end{array}$ & $\mathrm{C}_{22} \mathrm{H}_{24} \mathrm{~N}_{2} \mathrm{O}_{8}$ & $5 \mathrm{~g}$ \\
\hline
\end{tabular}

To the greatest extent possible, supplements were obtained from the same manufacturer to ensure consistency of the excipients. Acidophilus, garlic, and cinnamon was manufactured by SPROUTS INC (Phoenix, Arizona, USA); caprylic acid was manufactured by SOLARAY ${ }^{\circledR}$, and oil of oregano was manufactured by LIFETIME VITAMINS ${ }^{\circ}$ (Park City, Utah, USA). Table 1 summarizes the concentration strength of the active ingredients, as listed on the label of the over-the-counter supplements.

\section{Nutrient Agar Preparation}

Nutrient agar solution was prepared with a concentration of $23 \mathrm{~g}$ nutrient agar per liter of distilled water. The solution was boiled until it turned translucent. Next, it was autoclaved and poured onto petri dishes with a surface area of $1810 \mathrm{~mm}^{2}$ and a height of $4 \mathrm{~mm}$. Plates were allowed to cool and solidify for 4 hours.

\section{Bacterial and Yeast Culture}

A sterile disc inoculated with the chosen treatment was placed in the center of each petri dish. To create a bacterial lawn, each petri dish was streaked with 100 microliters of E. coli (beneficial intestinal bacteria) or B. megaterium (detrimental bacteria). Saccharomyces was activated with distilled water at $30^{\circ} \mathrm{C}$. To culture yeast, 100 microliters of Saccharomyces (yeast) was streaked onto each petri dish. Thus, each petri dish was either streaked with E. coli, B. megaterium, or Saccharomyces. Petri dishes were incubated upside down at $37^{\circ} \mathrm{C}$ for 4 days. E. coli and B. megaterium were obtained from Carolina Biological ${ }^{\circledR}$. Saccharomyces was obtained from Fleischmann ${ }^{\circledR}$. Each of the treatments were tested on 9 petri dishes: 3 plates with $E$. coli, 3 plates with $B$. megaterium, and 3 plates with Saccharomyces. Thus, each treatment was tested on each microbe in triplicate, making $\mathrm{n}=3$ for each combination of microbe and treatment. Each box and whisker figure represents data from experiments performed in triplicate.

\section{Zone of Inhibition Evaluation}

After petri dishes were incubated upside down at $37^{\circ} \mathrm{C}$ for 4 days, the effectiveness of the treatments was identified by measuring the surface area lacking any growth. This zone of inhibition was quantified by counting the squares of a graph paper that was cut to the exact size of the petri dish: 1810 $\mathrm{mm}^{2}$. The graph paper was placed under the petri dish, and the percentage of the petri dish without any growth was calculated and compared across treatments.

\section{RESULTS}

Overall, oil of oregano and acidophilus were the most effective treatments used as individual supplements

Among the individual supplements that were used as treatments, oil of oregano inhibited the maximum percentage of Saccharomyces (as shown in Figure 1) and B. megatarium growth (as shown in Figure 2). Acidophilus was the second most effective treatment at inhibiting Saccharomyces (Figure 1) and B. megaterium (Figure 2) growth. However, acidophilus was more effective than oil of oregano in aiding the growth of E. coli (as shown in Figure 3). The negative control yielded $0 \%$ growth inhibition for all microbes, and the positive control for $B$ megaterium and E. coli yielded $47 \%$ and $60 \%$ growth inhibition respectively.

Garlic, cinnamon, and caprylic acid did not affect the growth of B. megaterium

(Figure 2) or E. coli (Figure 3). Of these three supplements, caprylic acid was the only treatment that inhibited any Saccharomyces growth, but the zone of inhibition was much lower than the percentage of growth inhibition in the samples with oil of oregano and acidophilus (Figure 1).

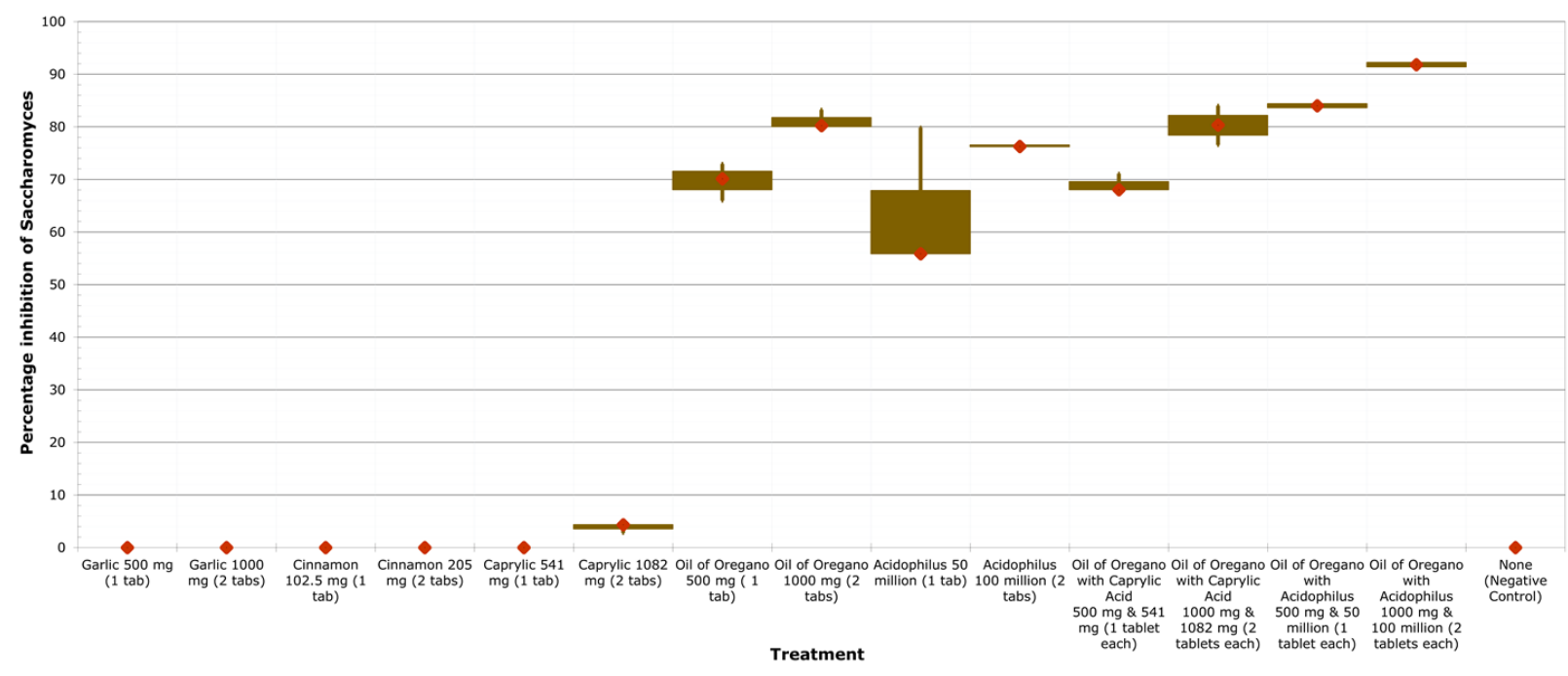

Figure 1 Effectiveness of treatments in inhibiting Saccharomyces growth. The relative frequency of inhibition in growth of Saccharomyces was determined by measuring the zone of inhibition in the petri dish and representing this value as a percentage. This percentage inhibition of Saccharomyces growth was calculated for all the treatments that were tested. 


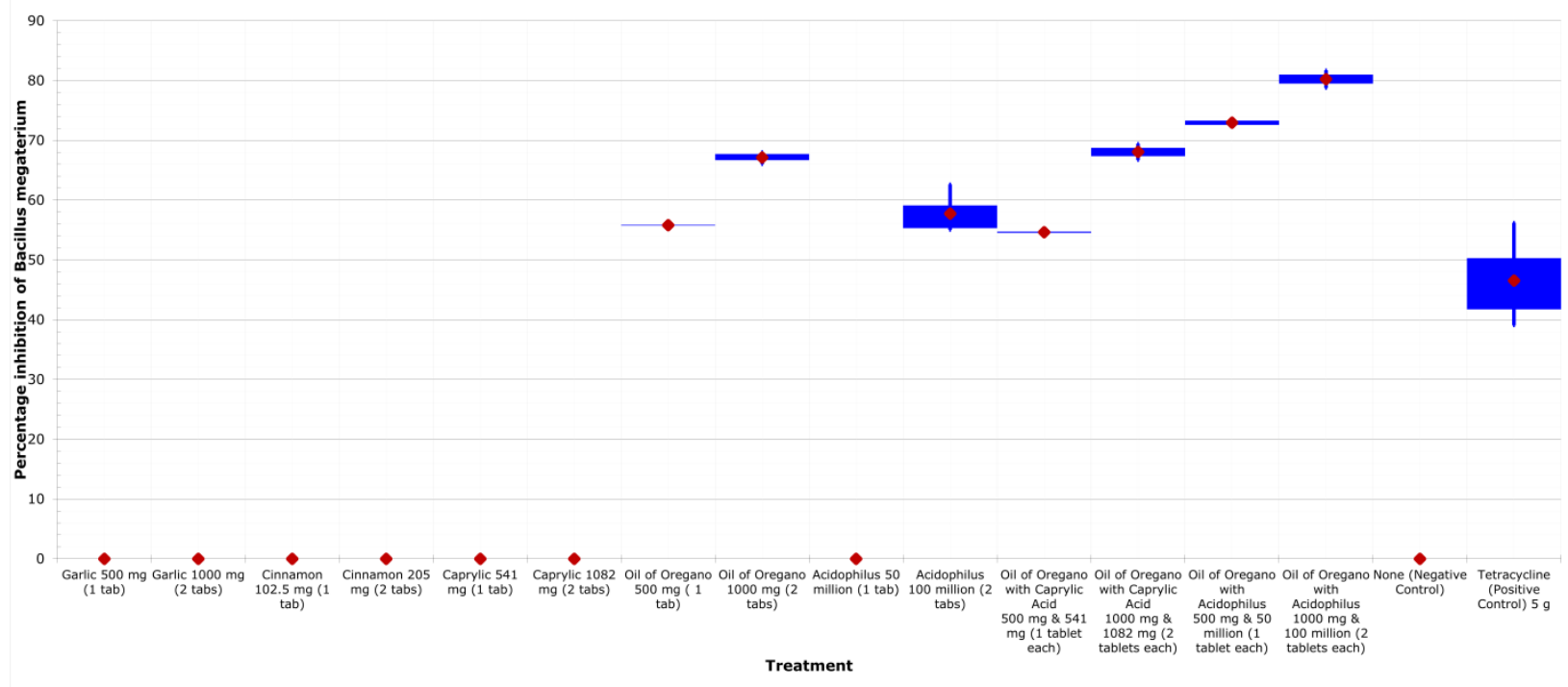

Figure 2 Effectiveness of treatments in inhibiting $B$. megatarium growth. The relative frequency of inhibition in growth of $B$. megatarium was determined by measuring the zone of inhibition in the petri dish and representing this value as a percentage. This percentage inhibition of $B$. megatarium growth was calculated for all the treatments that were tested.

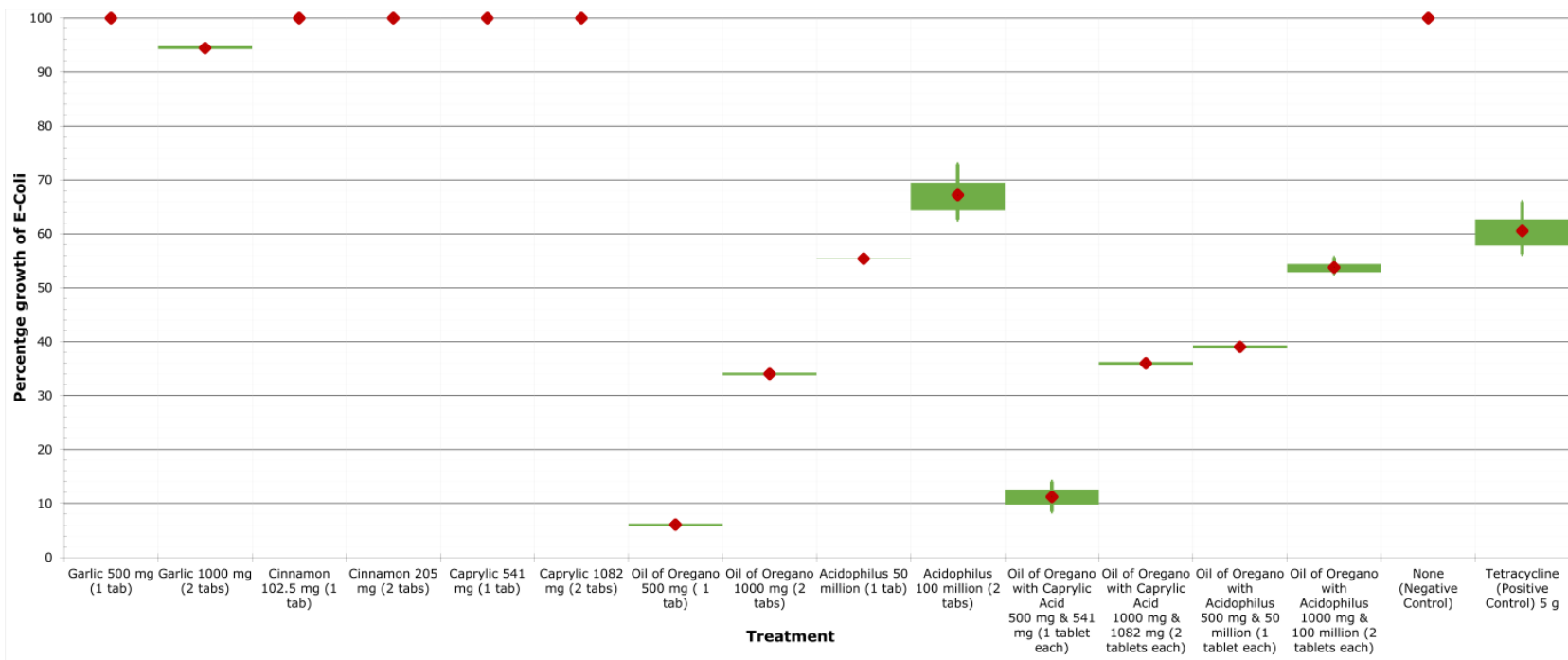

Figure 3 Effectiveness of treatments in proliferating E. coli. The relative frequency of growth of $E$. coli was determined by measuring the zone of inhibition in the petri dish and representing this value as a percentage. This percentage of $E$. coli growth was calculated for all the treatments that were tested.

The combination of oil of oregano with acidophilus was the most effective treatment

The highest concentration of oil of oregano with acidophilus was the most effective treatment; Saccharomyces growth was inhibited at $92.82 \%$ (Figure 1), $B$. megaterium growth was inhibited at $80.24 \%$ (Figure 2), and E. coli grew to fill $53.77 \%$ of the plate (Figure 3 ). Adding acidophilus to either oil of oregano or caprylic acid improved each antifungal's ability to inhibit Saccharomyces (Figure 1). However, adding caprylic acid to oil of oregano neither improved nor deteriorated oil of oregano's effectiveness at inhibiting growth of Saccharomyces (Figure 1) and B. megaterium (Figure 2). There was only a marginal increase in the growth of E. coli (Figure 3).

Increasing the concentrations of oil of oregano and acidophilus improved the potency of these treatments

Garlic, cinnamon, and caprylic acid had no impact on bacterial and yeast growth at both the lower and higher concentrations (Figure 1-3). However, doubling the concentration strength for acidophilus, oil of oregano, and their compounds improved their effectiveness by at least $10 \%$ (Figure 1-3). The most drastic effect was observed by increasing the concentration of acidophilus in B. megaterium cultures. Acidophilus had no impact at its lower concentration, but when the concentration was doubled, the treatment jumped from having no effective on $B$. megatarium growth to inhibiting $55.6 \%$ of growth (Figure 2 ).
Two methodologies were used to determine the most effective treatments overall

Table 2 summarizes the overall effectiveness of the treatments. When comparing single supplemental treatments with compounds, the most effective treatment in each category always included oil of oregano. The addition of acidophilus to oil of oregano resulted in increased inhibition of Saccharomyces over $B$ megaterium.

As shown in Table 2, there were 162 petri dish data samples altogether. The results of 3 samples $(n=3)$ for each of the 16 treatments and its associated microbe (Saccharomyces, B. megatarium, or E. coli) were averaged to calculate the area of growth or inhibition. The mean area of inhibition of $E$. coli was subtracted from the sum of the mean area of inhibition for Saccharomyces and $B$ megaterium to rank each treatment (column "Overall Rank"). An alternate overall ranking method which prioritizes Saccharomyces inhibition is also displayed, as the main purpose of this study to eliminate the growth of yeast. In this alternate ranking method, the area of inhibition of Saccharomyces growth was weighted twice over the inhibition of $B$. megatarium of growth of $E$. coli (column "Alternate Overall Rank").

Statistical Analysis 
Table 2 Two methodologies to rank the overall effectiveness of treatments

\begin{tabular}{|c|c|c|c|c|c|c|c|}
\hline \multirow{2}{*}{ Treatment and Concentration } & \multicolumn{3}{|c|}{$\begin{array}{l}\text { Zone of Inhibition }\left(\mathrm{mm}^{2}\right) \\
\text { (Average of Mean of the } 3 \text { samples per } \\
\text { treatment) }\end{array}$} & \multirow{2}{*}{$\begin{array}{c}\text { Overall } \\
\text { assessment } \\
\text { arithmentic } \\
(\mathbf{x}+\mathbf{y}-\mathbf{z})\end{array}$} & \multirow{2}{*}{$\begin{array}{l}\text { Overall Rank } \\
\text { (1 is most } \\
\text { effective })\end{array}$} & \multirow{2}{*}{$\begin{array}{l}\text { Alternate } \\
\text { Overall } \\
\text { assessment } \\
\text { arithmentic } \\
(2 \mathrm{x}+\mathrm{y}-\mathrm{z})\end{array}$} & \multirow{2}{*}{$\begin{array}{c}\text { Alternate } \\
\text { Overall } \\
\text { Rank } \\
\text { ( } 1 \text { is most } \\
\text { effective) }\end{array}$} \\
\hline & $\begin{array}{l}\text { Saccharomyces } \\
(\mathbf{x})\end{array}$ & $\begin{array}{c}\text { Bacillus } \\
\text { Megaterium } \\
(y)\end{array}$ & $\begin{array}{c}\text { Escherichia } \\
\text { Coli } \\
(\mathrm{z})\end{array}$ & & & & \\
\hline Garlic $500 \mathrm{mg}$ (1 tab) & 0 & 0 & 0 & 0 & 10 & 0 & 10 \\
\hline Garlic $1000 \mathrm{mg}$ (2 tabs) & 0 & 0 & 0 & 0 & 10 & 0 & 10 \\
\hline Cinnamon $102.5 \mathrm{mg}$ (1 tab) & 0 & 0 & 0 & 0 & 10 & 0 & 10 \\
\hline Cinnamon 205 mg (2 tabs) & 0 & 0 & 0 & 0 & 10 & 0 & 10 \\
\hline Caprylic Acid $541 \mathrm{mg}$ (1 tab) & 0 & 0 & 0 & 0 & 10 & 0 & 10 \\
\hline Caprylic Acid 1082 mg (2 tabs) & 69 & 0 & 0 & 69 & 9 & 138 & 9 \\
\hline Oil of Oregano $500 \mathrm{mg}$ ( $1 \mathrm{tab})$ & 1256 & 1010 & 1697 & 3963 & 1 & 1825 & 7 \\
\hline Oil of Oregano $1000 \mathrm{mg}$ (2 tabs) & 1485 & 1212 & 1193 & 3891 & 4 & 2989 & 5 \\
\hline Acidophilus 50 million ( $1 \mathrm{tab}$ ) & 1234 & 0 & 808 & 2042 & 8 & 1659 & 8 \\
\hline Acidophilus 100 million (2 tabs) & 1385 & 1017 & 555 & 2957 & 7 & 3232 & 3 \\
\hline $\begin{array}{l}\text { Oil of Oregano }(500 \mathrm{mg}) \text { with } \\
\text { Caprylic Acid }(541 \mathrm{mg}) \text { - One tablet } \\
\text { each }\end{array}$ & 1260 & 990 & 1610 & 3860 & 6 & 1900 & 6 \\
\hline $\begin{array}{l}\text { Oil of Oregano }(1000 \mathrm{mg}) \text { with } \\
\text { Caprylic Acid }(1082 \mathrm{mg}) \text { - Two } \\
\text { tablets each } \\
\text { Oil of Oregano }(500 \mathrm{mg}) \text { with }\end{array}$ & 1491 & 1225 & 1158 & 3875 & 5 & 3049 & 4 \\
\hline $\begin{array}{l}\text { Acidophilus ( } 50 \text { million) - One } \\
\text { tablet each }\end{array}$ & 1520 & 1315 & 1104 & 3938 & 2 & 3251 & 2 \\
\hline $\begin{array}{l}\text { Oil of Oregano }(1000 \mathrm{mg}) \text { with } \\
\text { Acidophilus }(100 \text { million }) \text { - Two } \\
\text { tablets each }\end{array}$ & 1661 & 1440 & 834 & 3935 & 3 & 3929 & 1 \\
\hline Tetracycline $5 \mathrm{~g}$ (positive control) & Not applicable & 942 & 710 & & & & \\
\hline No treatment (negative control) & 0 & 0 & 0 & & & & aUIC \\
\hline
\end{tabular}

There were 162 petri dish data samples altogether. Each of the 16 treatments (Table 2) was tested on 9 plates; there were three plates $(\mathrm{n}=3)$ for Saccharomyces, three plates $(\mathrm{n}=3)$ for B. megaterium, and three plates $(\mathrm{n}=3)$ for $E$. coli. Thus, each treatment had a total of 9 samples distributed across the 3 cultures. The box and whisker plots representing growth of each microbe for each treatment (Figures 1-3) display the mean, and the solid boxes represent values of the second and third quartile. The whiskers indicate values in the first and fourth quartile.

\section{DISCUSSION}

The highest concentration of oil of oregano with acidophilus was the most effective treatment, not supporting our hypothesis. In fact, oil of oregano by itself was an effective antifungal. This corroborates with other contemporary documented research of oil of oregano, which support its effectiveness as a bio fungicide against phytopathogenic fungi (Soylu et al., 2007) and against Candida (Manohar et al., 2001). Oil of oregano contains thymol, which causes cell membrane permeability in fungal cells and alters hyphal morphology. Eating a diet rich in oil of oregano (Origanum syriacum var. bevanii) and acidophilus or taking them as dietary supplement, especially with antibiotics, may reduce the risk of developing a yeast infection, as this combination resulted in minimal yeast and $B$. megaterium growth while greatly proliferating $E$. coli.

This study did not find the over-the-counter cinnamon supplement to be an effective antifungal. These findings could be another data point to consider in the scientific debate that questions the effectiveness of cinnamon as an effective antifungal (EBSCO Complementary and Alternative Medicine Review Board, 2014).

Our results indicate that the addition of bacterial probiotics in conjunction with an antifungal compound was the most effective treatment at curtailing fungal growth. Probiotics added friendly bacteria to recreate the ideal, oxygenated, nonacidic bacterial habitat; antifungals only killed off yeast without altering the acidic environment. In addition, probiotics did not interfere with the antifungal and increased friendly bacterial growth. In the absence of bacterial probiotics, a hazardous opportunity seemed to be opening up for the detrimental bacteria (i.e. $B$. megaterium) to proliferate. Thus, this study provides further evidence in the scientific debate supporting the addition of bacterial probiotics with antifungals to restore the balance of intestinal microbial.
Nevertheless, this study, only evaluated bacterial probiotics and did not explore those probiotics that contain yeast microbes as well. Medical practitioners have questioned the usage of probiotics with yeast in immunocompromised patients (Benchimol et al., 2005). In particular, several studies have identified probiotics containing Saccharomyces boulardii (Ultralevura manufactured by Bristol-Myers Squibb, New York City, New York, USA) as a risk factor for infection with Saccharomyces cervisiae (Munoz et al., 2005; Riquelme et al., 2003; Lestin et al., 2003; Cesaro et al., 2000).

Still, it is important to consider potential sources for error in this study. To accurately measure the zone of microbial inhibition, the outline of microbes was traced against a graph paper template, and the area was computed. The growth agar could have had unintended interference with the functionality of the treatments, although this is highly unlikely due to the ubiquitous nature of this growth medium with various types of microbes. Also, measuring the zone of inhibition is limited to growth inhibition and does not indicate whether microbes were killed or whether they were not allowed to grow in the first place. For these experiments, Saccharomyces and B. megaterium were used to represent detrimental yeast and bacteria respectively. Alternatively, samples of microbes cultured from the intestines of a sample of Candidemia patients would yield more accurate results pertaining to Candidemia infections specifically. Nonetheless, as many of these sources of error have minimal consequences or are highly unlikely to have significantly affected the results, findings form this study have relevance and important implications for future studies.

\section{CONCLUSIONS}

This study determined the combination of oil of oregano with acidophilus to be the most effective of all tested treatments in inhibiting Saccharomyces and $B$. megaterium growth while proliferating $E$. coli. The scope of this study did not include identifying the underlying mechanism that contributed to the observed results. A follow up study to comprehend the cellular mechanics that contribute to the effectiveness of the compound of oil of oregano and acidophilus against fungi is needed, as well as a more in depth exploration of the optimal concentration of each supplement. Results also encourage expanding the study to include other essential oil supplements, such as the oil from Fennel seeds. In the future, clinical evaluation of the treatment combination of oil of oregano and acidophilus with different concentrations is recommended, a necessary step 
before considering the incorporation of oil of oregano and cinnamon as part of the regular antibiotic regimen prescription.

Acknowledgement: The authors are grateful for access to Lynbrook High School's science facilities.

\section{REFERENCES}

Alangaden, G.J., 2011. Nosocomial Fungal Infections: Epidemiology, Infection Control, and Prevention. Infectious Disease Clinics of North America, 25(1) pp.201-225. http://dx.doi.org/10.1016/j.idc.2010.11.003

Ankandhk. Literature Review: Factors in selecting drugs in zone of inhibition advantages and disadvantages of zone of inhibition. Web. (Accessed December 2014). [Online open access link]

Bakker, N.D. Eric, 2012. Chronic Yeast Infection-Symptoms and Treatmen Solution For YOU. Web. (Accessed December 2014). [Online open access link] Balakrishnan, M., Floch, M.H. Prebiotics, probiotics and digestive health. Curr Opin Clin Nutr Metab Care. 2012, 15(6), 580-585. Review. http://dx.doi.org/10.1097/MCO.0b013e328359684f

Bassetti, M. et al., 2011. Epidemiology, Species Distribution, Antifunga Susceptibility and Outcome of Nosocomial Candidemia in a Tertiary Care Hospital in Italy. Spellberg, ed. PLoS ONE 6(9), p.e24198. http://dx.doi.org/10.1371/journal.pone.0024198 [Online open access link]

Benchimol, E.; Mack, D. R. Safety issues of probiotic ingestion. Probiotics: The hope, the hype, and the reality, series \#5. Practical Gastroenterology. [Online] 2005, Nov, 23-34. Web. [Online open access link]

Burton, Z. F. et al, 1997. Experiments in Molecular Biology: Biochemical Applications, Edition 1, Elsevier Science, pp.145-147. http://dx.doi.org/10.1136/mp.50.5.279-a [Online open access link]

Cesaro, S. et al., 2000. Saccharomyces cerevisiae fungemia in a neutropenic patient treated with Saccharomyces boulardii. Support Care Cancer, 8(6), pp.504-505. http://dx.doi.org/10.1007/s005200000123

Collado, M. et al., 2009. The Impact of Probiotic on Gut Health. CDM, 10(1), pp.68-78. http://dx.doi.org/10.2174/138920009787048437

EBSCO Complementary and Alternative Medicine Review Board - NYU Langone Medical Center. Cinnamon. Web. Updated September 2014. (Accessed December 2014).

Fridkin, S.K., 2005. Candidemia is Costly--Plain and Simple. Clinical Infectious Diseases, 41(9), pp.1240-1241. http://dx.doi.org/10.1086/496935

GORBACH, S., 2000. Probiotics and gastrointestinal health. The American Journal of Gastroenterology, 95(1), pp.S2-S4. http://dx.doi.org/10.1016/s00029270(99)00806-0

Hawksworth, D.L., 2001. The magnitude of fungal diversity: the 1.5 million species estimate revisited. Mycological Research, 105(12), pp.1422-1432 http://dx.doi.org/10.1017/s0953756201004725

Horn, D.L. et al., 2009. Epidemiology and Outcomes of Candidemia in 2019 Patients: Data from the Prospective Antifungal Therapy Alliance Registry. Clinical Infectious Diseases, 48(12), pp.1695-1703. http://dx.doi.org/10.1086/599039

Jensen, J.-U.S. et al., 2015. Invasive Candida Infections and the Harm From Antibacterial Drugs in Critically Ill Patients. Critical Care Medicine, 43(3), pp.594-602. Available at: http://dx.doi.org/10.1097/ccm.0000000000000746

Kauffman, C.; Marr, K.; Thomer, A. Treatment of candidemia and invasive candidiasis in adults; UpToDate: Waltham, MA. 2014. [Online].

Klajn, R. Institute of Organic Chemistry, PAN. Antimicrobial properties of Tetracyclines towards bacteria. Web. (Accessed December 2014). [Online access link].

Kumar, S. et al., 2013. Probiotic Use and Prevalence of Candidemia and Candiduria in a PICU. Pediatric Critical Care Medicine, 14(9), pp.e409-e415. http://dx.doi.org/10.1097/pcc.0b013e31829f5d88

Lestin, F. et al., 2003. Fungemia after oral treatment with Saccharomyces boulardii in a patient with multiple co-morbidities. Dtsch Med Wochenschr, 128(48), 2531-2533. http://dx.doi.org/10.1055/s-2003-44948

Manohar, V. et al., 2001. Antifungal activities of origanum oil against Candida albicans, Molecular and Cellular Biochemistry. 228 (1/2), pp.111-117. http://dx.doi.org/10.1023/a:1013311632207

Mikulska, M. et al., 2012. Occurrence, presentation and treatment of candidemia Expert Review of Clinical Immunology, 8(8), pp.755-765 http://dx.doi.org/10.1586/eci.12.52

Miranda, L.N. et al., 2009 Candida colonisation as a source for candidaemia. Journal of Hospital Infection, 72(1), pp.9-16. http://dx.doi.org/10.1016/j.jhin.2009.02.009

Munoz, P. et al., 2005. Saccharomyces cerevisiae Fungemia: An Emerging Infectious Disease. Clinical Infectious Diseases, 40(11), pp.1625-1634. http://dx.doi.org/10.1086/429916

NHS choices. Antifungal medicines-Side effects and interactions with other drugs. Web. (Accessed September 2015). [Online access link].

Nucci, M. \& Anaissie, E., 2001. Revisiting the Source of Candidemia: Skin or Gut? Clinical Infectious Diseases, 33(12), pp.1959-1967. http//dx doi.org/10.1086/323759
Puzniak, L. et al., 2004. Has the Epidemiology of Nosocomial Candidemia Changed? Infection Control and Hospital Epidemiology, 25(8), pp.628-633. http://dx.doi.org/10.1086/502452 [Online open access link]

Riquelme, A.J. et al., 2003. Saccharomyces cerevisiae Fungemia After Saccharomyces boulardii Treatment in Immunocompromised Patients. Journal of Clinical Gastroenterology, 36(1), pp.41-43. http://dx.doi.org/10.1097/00004836200301000-00013

Rolfe, R. D. The role of probiotic cultures in the control of gastrointestinal health. J Nutr. 2000, 130(2), 396S-402S. Review. PubMed PMID: 10721914

Soylu, S. et al., 2007. Antifungal effects of essential oils from oregano and fennel on Sclerotinia sclerotiorum . Journal of Applied Microbiology, 103(4) pp.1021-1030. http://dx.doi.org/10.1111/j.1365-2672.2007.03310.x

Spampinato, C. \& Leonardi, D., 2013. Candida Infections, Causes, Targets, and Resistance Mechanisms: Traditional and Alternative Antifungal Agents. BioMed Research International, 2013, pp.1-13. http://dx.doi.org/10.1155.2013/204237

Tani, N. et al., 2012. Antifungal activities of novel non-azole molecules against S. cerevisiae and C. albicans. European Journal of Medicinal Chemistry, 47, pp.270-277. http://dx.doi.org/10.1016/j.ejmech.2011.10.053

The University of Adelaide, Adelaide, 2014, Mycology online: Candidiasis. Web [Open online access link]. (Accessed December 2014).

U.S. National Library of Medicine, MedlinePlus. Tetracycline. Web. [Open online access link]. (Updated 2010. Accessed December 2014).

Verna, E.C. \& Lucak, S., 2010. Use of probiotics in gastrointestinal disorders: what to recommend? Therapeutic Advances in Gastroenterology, 3(5), pp.307319. http://dx.doi.org/10.1177/1756283x10373814

Wang, G. et al., 2012. Mechanisms, clinically curative effects, and antifungal activities of cinnamon oil and pogostemon oil complex against three species of Candida. Journal of Traditional Chinese Medicine, 32(1), pp.19-24 http://dx.doi.org/10.1016/s0254-6272(12)60026-0

Wang, S.-Y., Chen, P.-F. \& Chang, S.-T., 2005. Antifungal activities of essential oils and their constituents from indigenous cinnamon (Cinnamomum osmophloeum) leaves against wood decay fungi. Bioresource Technology, 96(7), pp.813-818. http://dx.doi.org/10.1016/j.biortech.2004.07.010

Warnock, D.W., 2007. Trends in the Epidemiology of Invasive Fungal Infections Nippon Ishinkin Gakkai Zasshi, 48(1), pp.1-12 http://dx.doi.org/10.3314/jjmm.48.1

Wilson, L.S. et al., 2002. The Direct cost and Incidence of Systemic Fungal Infections. Value in Health, 5(1), pp.26-34. http://dx.doi.org/10.1046/j.15244733.2002.51108.x

Zaoutis, T.E. et al., 2005. The Epidemiology and Attributable Outcomes of Candidemia in Adults and Children Hospitalized in the United States: A Propensity Analysis. Clinical Infectious Diseases, 41(9), pp.1232-1239. http://dx.doi.org/10.1086/496922 